\title{
Normal Aging Delays and Compromises Early Multifocal Visual Attention during Object Tracking
}

\author{
Viola S. Störmer ${ }^{1}$, Shu-Chen $\mathbf{L i}^{1}$, Hauke R. Heekeren ${ }^{1,2}$, \\ and Ulman Lindenberger ${ }^{1}$
}

\begin{abstract}
Declines in selective attention are one of the sources contributing to age-related impairments in a broad range of cognitive functions. Most previous research on mechanisms underlying older adults' selection deficits has studied the deployment of visual attention to static objects and features. Here we investigate neural correlates of age-related differences in spatial attention to multiple objects as they move. We used a multiple object tracking task, in which younger and older adults were asked to keep track of moving target objects that moved randomly in the visual field among irrelevant distractor objects. By recording the brain's electrophysiological responses during the tracking period, we were able to delineate neural processing for targets and distractors at early stages of visual processing $(\sim 100-$
\end{abstract}

\section{INTRODUCTION}

Common daily activities such as driving a car in traffic require the ability to attend to and monitor multiple moving objects among other irrelevant objects in the visual field. The ability to keep track of moving objects among distractors is limited (Cavanagh \& Alvarez, 2005; Pylyshyn \& Storm, 1988) and undergoes age-related decline (Störmer, Li, Heekeren, \& Lindenberger, 2011; Sekuler, McLaughlin, \& Yotsumoto, 2008; Trick, Perl, \& Sethi, 2005). Older adults are usually more susceptible to distracting information than younger adults (for a review, see Guerreiro, Murphy, \& Van Gerven, 2010; Mager et al., 2007; Nagel, Werkle-Bergner, Li, \& Lindenberger, 2007; Zysset, Schroeter, Neumann, \& von Cramon, 2007; Kramer \& Strayer, 2001; West \& Alain, 2000; Maylor \& Lavie, 1998; Madden \& Gottlob, 1997; Rabbitt, 1965). This age-related increase in distractibility may make it more difficult for older adults to selectively keep track of relevant moving objects among distractor objects. Selective processing is commonly thought to involve both the enhancement of neural responses to relevant information and the suppression of neural responses to irrelevant information (Gazzaley, Cooney, McEvoy, Knight, \& D’Esposito, 2005; Hillyard,

\footnotetext{
${ }^{1}$ Max Planck Institute for Human Development, Berlin, Germany,

${ }^{2}$ Freie Universität Berlin
}

$300 \mathrm{msec}$ ). Older adults showed less selective attentional modulation in the early phase of the visual P1 component (100-125 msec) than younger adults, indicating that early selection is compromised in old age. However, with a 25 -msec delay relative to younger adults, older adults showed distinct processing of targets (125$150 \mathrm{msec}$ ), that is, a delayed yet intact attentional modulation. The magnitude of this delayed attentional modulation was related to tracking performance in older adults. The amplitude of the N1 component (175-210 msec) was smaller in older adults than in younger adults, and the target amplification effect of this component was also smaller in older relative to younger adults. Overall, these results indicate that normal aging affects the efficiency and timing of early visual processing during multiple object tracking.
Vogel, \& Luck, 1998; Duncan, Humphreys, \& Ward, 1997). Whereas the enhancement of relevant information seems to be relatively intact in old age, efficient neural suppression of irrelevant information seems to be particularly compromised (Gazzaley, Cooney, Rissman, \& D'Esposito, 2005; Alain \& Woods, 1999; Czigler, Csibra, \& Ambro, 1994; see also Fabiani, Low, Wee, Sable, \& Gratton, 2006). This age-related decrease in suppressing irrelevant information has been interpreted as one of the key mechanisms that underlie older adults' deficits in a wide range of cognitive functions (Gazzaley, Cooney, Rissman et al., 2005; Hasher \& Zacks, 1988) and may also contribute to the age-related decline in selectively tracking moving objects.

Attentional selection operates at multiple stages during sensory processing and beyond, making it difficult to pinpoint the loci and time points of the age-related increase in distractibility (Kastner \& Pinsk, 2004; Martinez et al., 1999). Declines in selective processing of stimuli among older adults could, for instance, result from selection deficits at early stages of perceptual processing, at subsequent cognitive stages that may involve deciding or responding, or in the interaction dynamics between these stages. Two recent fMRI studies point to age-related impairments in effects of attentional control at the perceptual processing stage. Schmitz, Cheng, and De Rosa (2010) examined adaptation effects during a visual discrimination task in younger and older adults. Younger and older 
participants were asked to discriminate face stimuli that were overlaid on house stimuli. Schmitz and colleagues reported that older adults showed more neural adaptation to the to-be-ignored houses in the parahippocampal place area and less neural adaption effects to the to-be-attended faces in the fusiform face area relative to younger adults. Schmitz et al.'s (2010) findings suggest that the age-related decline in top-down attentional selection affects processing in visual cortex. Similarly, Gazzaley, Cooney, Rissman et al., (2005) investigated modulations of neural activity within visual cortex during the encoding phase of a working memory task. When processing to-be-remembered images (i.e., faces/scenes), both younger and older adults showed an increase in neural activity relative to a passive viewing condition. When processing to-be-ignored images, however, older adults did not show modulations in neural activity relative to a passive viewing condition, whereas younger adults showed suppression of neural activity in visual cortex.

Both studies converge on the proposition that agerelated impairments in top-down attentional selection influence processing in visual cortex. However, the sluggishness of the hemodynamic responses makes it difficult to examine the time course of such a deficit with fMRI. In younger adults, electrophysiological studies with high temporal resolution (i.e., milliseconds) have consistently demonstrated that selective attention can operate at early stages by gating the neural response to relevant stimuli relative to irrelevant stimuli (Hillyard \& AnlloVento, 1998; Heinze et al., 1994). Increased neural activity measured over visual cortex has been found for attended stimuli compared with unattended stimuli within the first $300 \mathrm{msec}$ of processing (Hillyard, Mangun, Woldorff, \& Luck, 1995; Luck, Heinze, Mangun, \& Hillyard, 1990), calling for electrophysiological studies on early visual stimulus processing in the elderly as well.

Gazzaley and colleagues (2008) investigated early cortical processing in a group of older adults by measuring the electrophysiological responses over occipital cortex during a visual working memory task. Younger and older adults were presented with a stream of faces and scenes and were instructed to remember one stimulus type and ignore the other or to passively view both stimuli. Gazzaley and colleagues recorded ERPs time-locked to the different stimulus types and found an age-related deficit in suppressing the to-be-ignored stimuli in early visual processing ( 100-300 msec), but not at later stages of processing ( $\sim 500-650 \mathrm{msec})$. The age-related deficits in attentional selection were reflected as reduced amplitude modulations of the P1 component and as latency differences of the N1 component in older adults. The authors concluded that mechanisms for suppressing irrelevant information are not abolished with advancing age, but rather delayed in time. Gazzaley et al. (2008) also observed that older adults were not able to reach younger adults' performance, although they managed to suppress irrelevant information at later processing stages. Apparently, older adults' deficit in early selection could not be fully compensated by later processing. In another study, Zanto, Toy, and Gazzaley (2010) showed similar age-related latency delays in the so-called selection negativity, a neural marker of attentional selection within the time range of the N1 component, during working memory encoding of motion and color stimuli. Together, these studies demonstrate that agerelated deficits in attentional selection occur during early stages of visual processing for both complex images (i.e., faces, scenes) and features (i.e., color, motion).

In these tasks, relevant and irrelevant stimuli were presented successively, rendering generalizations to everyday visual perception difficult. The human visual system is usually confronted with competing stimuli concurrently rather than sequentially. Distracting information that is presented simultaneously with relevant information causes considerably more interference compared with when relevant and irrelevant information are presented successively (e.g., Kritikos, McNeill, \& Paviis, 2008). Another recent EEG study investigated age-related differences in the processing of to-be-ignored faces in a face-name version of the Stroop task in which attended and unattended stimuli were presented simultaneously (de Fockert, Ramchurn, van Velzen, Bergstrom, \& Bunce, 2009). Older adults showed greater amplitudes of the N1 component in response to the to-be-ignored faces than younger adults, suggesting that they processed the to-be-ignored information to a greater extent than younger adults, again pointing to an age-related deficit in suppression. The interpretation of this effect needs to be considered with caution, however, because information about age differences in ERP responses to faces at baseline was not provided.

Taken together, age differences in early cortical processing of relevant and irrelevant information have been investigated using working memory tasks in which stimuli were presented successively during the encoding phase (Zanto et al., 2010; Gazzaley et al., 2008; but see also Jost, Bryck, Vogel, \& Mayr, 2011) or in attention tasks that used static stimuli (de Fockert et al., 2009). Both fMRI and ERP studies suggest that normal aging compromises top-down attentional modulations at early stages of perceptual processing for objects (e.g., faces/scenes) and features (e.g., motion, color). However, the time course and magnitude of age-related deficits in early perceptual processing in the context of multifocal spatial attention and, more specifically, attending to objects as they move in the visual field, remain to be determined.

\section{Aims and Hypotheses}

In this study, we investigated the neural correlates of early visual processing using an attentional tracking task in younger and older adults. We used a variant of the multiple object tracking (MOT) task, in which moving target objects have to be tracked among identical moving distractor objects in the visual field for several seconds (Pylyshyn \& Storm, 1988). This task requires observers to constantly 
select and update the locations of targets among distractors, putting a high demand on top-down attentional control (Cavanagh \& Alvarez, 2005). In our version of the task, observers were required to track two target objects among four moving distractors and four stationary distractors for $10 \mathrm{sec}$ (cf. Drew, McCollough, Horowitz, \& Vogel, 2009). To determine whether older adults differed in early cortical processing from younger adults, we recorded the brain's electrophysiological response during the tracking period. The analysis focused on early visually evoked P1 and N1 components of the ERP that are known to be modulated by selective attention in younger adults during MOT (Drew et al., 2009; for modulation of the N1 component, see also Doran \& Hoffman, 2010). These components reflect early processing of visual stimuli in extrastriate cortex and consist of a positive deflection at around $100 \mathrm{msec}$ (P1 component) and a negative deflection at around $180 \mathrm{msec}$ (N1 component) after stimulus onset (Heinze et al., 1994; Heinze, Luck, Mangun, \& Hillyard, 1990; Luck et al., 1990). ERP amplitudes of the $\mathrm{P} 1$ and N1 components have been found to be larger for attended stimuli compared with unattended stimuli, indicating a relative enhancement of the neural response to relevant information (Hillyard \& Anllo-Vento, 1998). Hence, these attentional modulations of the ERP amplitudes serve as valid indicators for investigating age-related differences in early selection processes.

In light of earlier evidence (Störmer et al., 2011; Sekuler et al., 2008; Trick et al., 2005), we expected that older adults would track targets less well than younger adults. We expected that younger adults would show an increase in neural processing of target objects relative to both types of distractors (moving and stationary), as reflected in an amplitude enhancement of the P1 and N1 components for targets relative to any distractor (c.f., Doran \& Hoffman, 2010; Drew et al., 2009). Such a result would indicate enhanced target processing as reflected in larger target-related ERP amplitudes relative to responses to stationary distractors. Furthermore, no amplitude differences between moving and stationary distractors would suggest that moving distractors, although sharing the moving feature with the targets, are processed at the same level as stationary distractors and thus efficiently suppressed.

We expected that the results for older adults would differ from the pattern observed in younger adults in three main ways. First, we hypothesized that older adults would show less specific selection than younger adults. In particular, we expected that targets would be enhanced relative to stationary distractors but that moving distractors would be processed less differently from moving targets, hence not suppressed to the level of stationary objects. Second, based on recent findings of delayed suppression in older adults (e.g., Gazzaley et al., 2008), we hypothesized that to the extent that moving distractors were suppressed in older adults, this would occur later in time in older adults relative to younger adults. To in- vestigate the specificity of delayed target selection, we examined the time course of the ERP amplitude difference waveforms between target and distractor objects. Third, we expected that the efficiency in suppressing moving distractors would vary substantially among older adults. Even within positively selected samples of healthy older adults, a sizeable degree of heterogeneity can be expected (Lindenberger, Burzynska, \& Nagel, in press; Nagel et al., 2009; Gazzaley, Cooney, McEvoy, et al., 2005). To explore this heterogeneity in relation to selective attention, we conducted correlational and subgroup analysis. For the latter, we split the total sample of older adults into highand low-performing subgroups. We expected that older adults who showed more effective suppression of moving distractors would also show better tracking performance.

\section{METHODS \\ Participants}

Forty-seven older and 42 younger adults participated in the study after they had given informed consent. Data from 4 younger and 10 older participants were excluded from further analysis because more than $40 \%$ of the EEG recording trials had to be rejected because of artifacts (e.g., eye movements, blinks, muscle tension). Of the remaining 38 younger adults (18 women, ages 19-32 years; mean age $=26[ \pm 2.9]$ years) and 37 older adults (17 women, ages $62-76$ years; mean age $=$ $69[ \pm 3.5]$ years) all were right-handed, reported normal hearing, and had normal or corrected-to-normal vision. Vision was assessed before the experiment. Distance visual acuity was measured for the left and right eye separately using standard tables of Landolt rings with a standard distance of $6 \mathrm{~m}$ (Geigy, 1977). Close visual acuity was measured binocularly by having participants read digits at regular reading distance $(\sim 30 \mathrm{~cm})$. Color vision was assessed using a set of six color panels (Velhagen \& Broschmann, 2005). All measurements were taken with optimal correction. In comparison with younger adults, older adults had lower scores of close, $F(1,73)=46.92$, $p<.05$, and distant visual acuity, $F(1,73)=37.61, p<$ .05 , as well as color vision, $F(1,73)=6.77, p<.05$. However, all participants included in the final sample were within the normal range of vision (close vision: $v>0.5$; distant vision: 6/6; cf. Cline, Hofstetter, \& Griffin, 1997) and could report at least four of six color panels correctly (see Table 1 for details). In a separate behavioral assessment session, participants were assessed on marker tests of crystallized intelligence (Lehrl, 1977) and perceptual speed (Wechsler, 1958). As to be expected from findings derived from lifespan samples (e.g., Li et al., 2004), older adults attained lower scores in perceptual speed and higher scores in verbal knowledge than younger adults. There was no difference in years of education between the two age groups (see Table 1 for demographic information). The study was approved by the 
Table 1. Demographic and Basic Cognitive Characteristics of Sample

\begin{tabular}{lcc}
\hline & $\begin{array}{c}\text { Younger Adults, } \\
M(S D)\end{array}$ & $\begin{array}{c}\text { Older Adults, } \\
M(S D)\end{array}$ \\
\hline Age, years & $25.8(2.9)$ & $68.9(3.5)$ \\
Years of education & $13.5(2.4)$ & $12.5(4.2)$ \\
$\begin{array}{l}\text { Identical pictures } \\
\quad\left(\text { processing speed) }^{\mathrm{a}}\right.\end{array}$ & $35.3(4.6)$ & $23.1(3.4)$ \\
$\begin{array}{l}\text { Spot-a-word } \\
\quad\left(\text { pragmatics }^{\mathrm{a}}\right)\end{array}$ & $18.4(5.0)$ & $22.5(5.9)$ \\
Close vision $^{\mathrm{b}}$ & $0.85(0.2)$ & $0.63(0.1)$ \\
Distant vision $^{\mathrm{b}}$ & $1.9(0.3)$ & $1.3(0.3)$ \\
Color vision $^{\mathrm{c}}$ & $5.8(0.4)$ & $5.3(0.9)$ \\
\hline
\end{tabular}

${ }^{\text {a }}$ Performance of the identical pictures and spot-a-word tasks is provided in raw scores.

${ }^{b}$ Visual acuity is reported in the decimal system.

${ }^{\mathrm{c}}$ Color vision is indicated as the number of correctly reported color panels (out of six total).

ethics committee of the Max Planck Institute for Human Development.

\section{Stimuli and Procedure}

The experiment was conducted in an electrically shielded chamber and contained a 19-in. computer display. All stimuli were presented on a gray background $\left(10.5 \mathrm{~cd} / \mathrm{m}^{2}\right)$ in regions subtending $16^{\circ} \times 13^{\circ}$ visual angle. Throughout the experiment, a small black fixation cross $\left(0.32^{\circ} \times\right.$ $0.32^{\circ}$ ) was presented in the center of the display. The entire experiment consisted of four blocks of 24 trials each. At the start of each trial, 10 black disks $\left(0.81^{\circ} \times 0.81^{\circ}\right)$ were presented at random locations within the viewing area (see Figure 1). Two of the 10 disks were briefly marked in red $\left(30 \mathrm{~cd} / \mathrm{m}^{2}\right.$; red, green, blue: 2550 0), designating them as targets. The two targets turned back to black after 400 msec and started moving randomly across the screen together with four of the eight distractor disks (hereafter "moving distractors"). The other four distractor disks remained at their initial position until the end of the trial (hereafter "stationary distractors"). The trajectories of the moving disks were linear and changed only when the disks made contact with the outer barrier of the viewing field or with each other, so to avoid occlusion. The disks moved at a constant speed of $1 \%$ sec. Movement stopped after $10 \mathrm{sec}$, and one disk became red, marking it as a test probe. The test probe was one of the original targets on half of the trials and one of the moving distractors on the remaining trials. The observer was instructed to indicate whether the probed disk was a target or not by pressing a left or right button on a keyboard with the left or right index finger. Response buttons were counterbalanced between participants.
During the movement period, task-irrelevant white probes appeared briefly $(150 \mathrm{msec})$ at random time intervals (ITI $=800-1000 \mathrm{msec}$, rectangular distribution) on the two targets, two of the moving distractors, and two of the stationary distractors. The probes were the same size as the disks, thereby overlapping with them completely. Each trial included three of each type of probe: target probes, moving distractor probes, and stationary distractor probes. The order of the probe types was randomized. The task-irrelevant probes were included to assess the neural processing of the different disks during the tracking period. In particular, the probes allowed us to measure the visually evoked P1 and N1 components of the ERP elicited by either probe type.

\section{Behavioral Data Analysis}

To examine whether younger and older adults differed in their performance and RT, response accuracy (\% correct) and median RT were analyzed using ANOVA with Age Group as a between-subject factor.

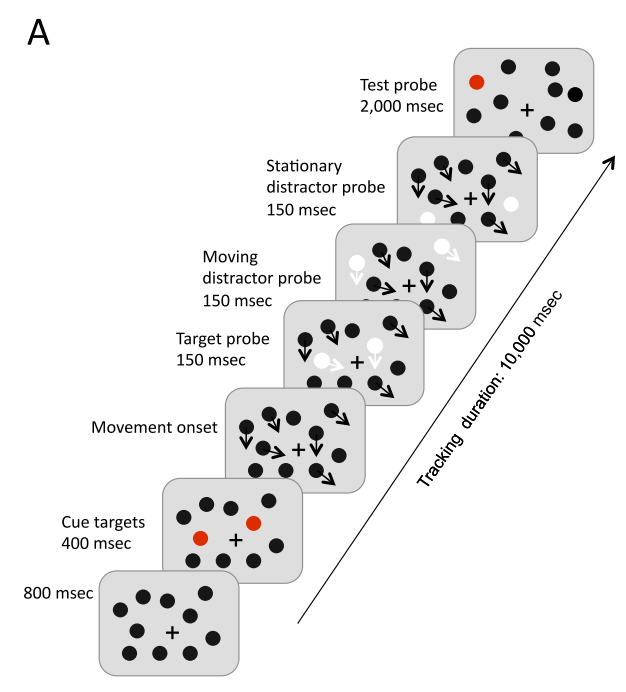

B

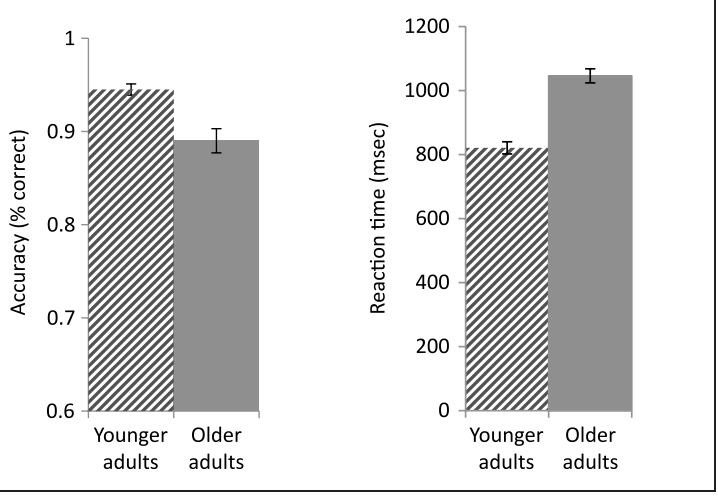

Figure 1. (A) The sequence of events on a trial of the multiple-object tracking task. (B) Tracking accuracy (\% correct) and correct RT (msec) for younger and older adults. 


\section{Recording and Analysis}

Electrophysiological recordings were obtained from $64 \mathrm{Ag} /$ $\mathrm{AgCl}$ electrodes placed according to the 10-10 system in an elastic cap (BrainAmp DC amplifiers, Brain Products $\mathrm{GmbH}$, Gilching, Germany). All EEG signals were referenced to the right mastoid. The horizontal EOG was recorded bipolarly using two electrodes positioned lateral to the external canthi; vertical EOG was recorded using one electrode below the left eye. Electrode impedances were kept below $5 \mathrm{k} \Omega$. All signals were recorded with a bandpass of 0.1-100 Hz and digitized at a rate of $1000 \mathrm{~Hz}$.

Artifact rejection and ERP averaging were performed with ERPSS (University of California, San Diego). The EEG and EOG epochs were averaged over 3-sec epochs that started $1.5 \mathrm{sec}$ before onset of the probe. Epochs that contained ocular artifacts or amplifier blocking were excluded from further analysis. Horizontal and vertical eye movements were detected using a semiautomated procedure, in which differences between the minimum and maximum voltages on the EOG channels were compared with a threshold value. Threshold values were determined by visually inspecting the continuous EEG and EOG for each individual separately (for a similar procedure, see Green, Conder, \& McDonald, 2008). The minimum and maximum voltages were selected within an 800-msec time window within the recording epoch that started $200 \mathrm{msec}$ before probe onset. Artifact-free data were then used to create averaged ERP waveforms. Separate averages were created for target probes, moving distractor probes, and stationary distractor probes. The averaged waveforms were digitally low-pass filtered (using the $3 \mathrm{~dB}$ cutoff at $25 \mathrm{~Hz}$ ) and digitally rereferenced to the average of the left and right mastoid.

To characterize the scalp topography of the ERP activities, isopotential contour maps for the mean voltages for the different conditions were created using Advance Source Analysis software (ASA4, Advance Neuro Technologies B.V., Enschede, Netherlands). Maps were plotted separately for younger and older adults in three different time intervals (100-125, 125-150, and 185-210 msec) based on the peaks of activity observed in the mean ERP waveforms.

\section{ERP Data Analysis}

On the basis of the voltage distribution in younger and older adults (see Figure 2), the P1 component was examined at parietal-occipital and central-parietal sites, and the N1 component was examined at lateral parietaloccipital sites. To determine at which time points selective target processing occurred, difference waveforms were computed for the target-minus-moving-distractor ERP waveforms in younger and older adults. The time windows of interest were defined based on the difference waveforms observed in the grand-averaged waveforms of the group of younger adults: The early P1 effect was defined as the mean amplitude from 100 to $125 \mathrm{msec}$ post probe onset at four parietal-occipital electrodes $\mathrm{PO} 3 / \mathrm{PO} 4$ and $\mathrm{PO} 7 /$ PO8 and four central-parietal electrode sites CP1/CP2 and $\mathrm{C} 1 / \mathrm{C} 2$. The N1 effect was defined as the mean amplitude from 185 to $210 \mathrm{msec}$ at four lateral parietal-occipital electrode sites PO7/PO8 and P7/P8.

To explicitly address the hypothesis of an age-related delay in selective target processing, difference waveforms were analyzed in a second step. As depicted in Figure 3B, older adults exhibited amplitude differences between targets and moving distractors at similar time points as younger adults at parietal-occipital electrode sites. However, the time course of the difference wave deviated from what was observed in younger adults at central-parietal electrode
Figure 2. Topographical voltage maps of the ERP waveforms for younger (left) and older adults (right). Maps display back views of the scalp for the voltage distribution for the ERPs elicited by target probes (left), moving distractor probes (middle), and stationary distractor probes (right) at three different time intervals: $100-125,125-150$, and $185-210$ msec. Note that the scales differ between age groups and conditions.

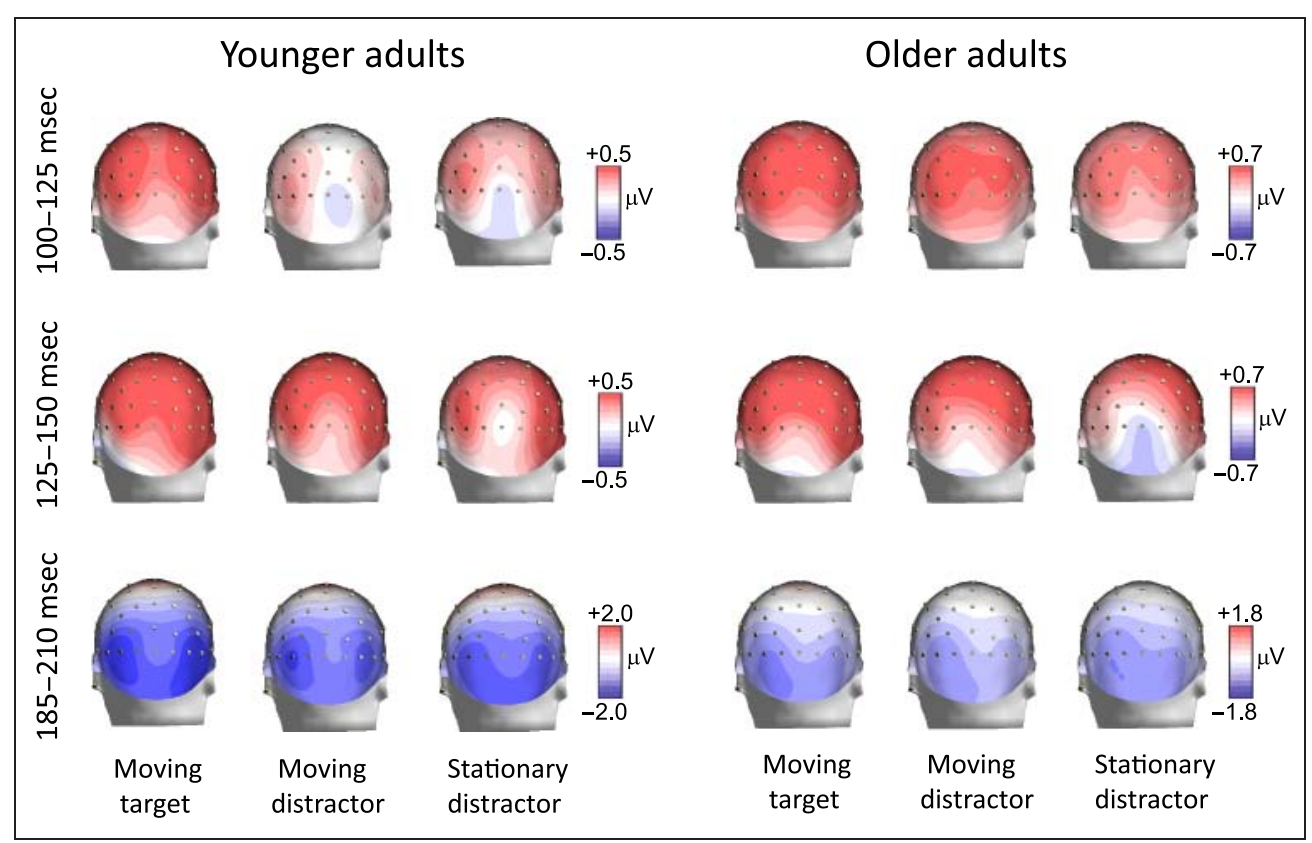




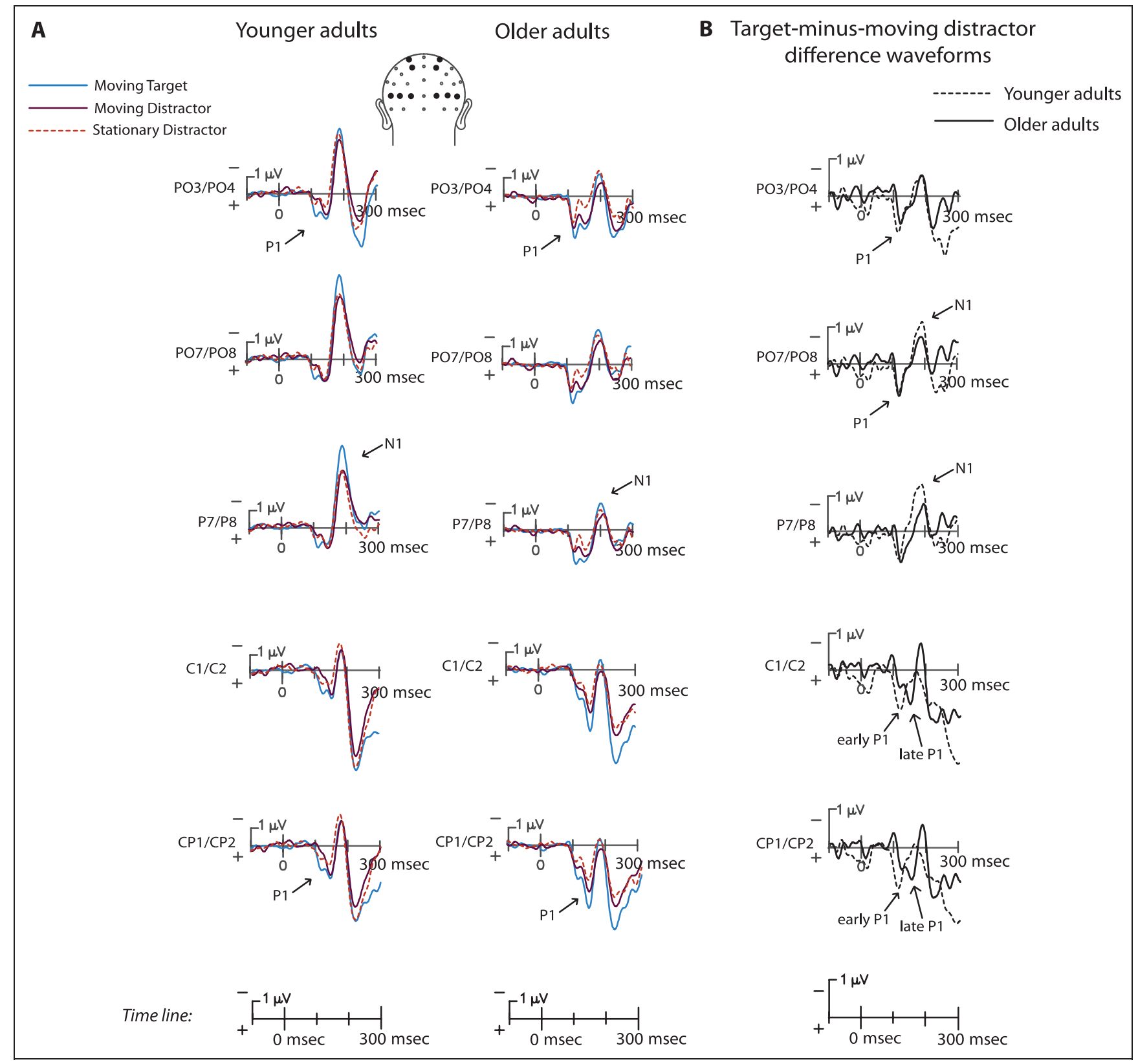

Figure 3. ERP waveforms at occipital-parietal and parietal-central electrode sites. ERPs were collapsed across electrode hemisphere. (A) ERPS elicited by the different probe types for younger (left) and older (right) adults. (B) Target-minus-moving distractor difference waveforms for younger (dashed gray) and older adults (solid black).

sites, peaking about $25 \mathrm{msec}$ later in older relative to younger adults. Thus, we further analyzed the time window of $125-150$ msec at central-parietal sites in older adults.

Mean amplitudes were measured separately for each participant and each probe type in the time intervals and electrode sites of interest. The resulting mean amplitudes were first analyzed with a mixed between-within ANOVA with Age Group as a between-subject factor and Probe Type (moving target, moving distractor, stationary distractor) and Electrode Location as within-subject factors for each time interval separately. When reliable age effects were ascertained, follow-up analyses were done separately for each age group. When necessary, follow-up pairwise comparisons were performed to identify at which levels and locations the effects were present. When the sphericity assumption was violated $(p<.05)$, Greenhouse-Geisser corrected $p$ values were applied. In addition, the peak latencies of the positive and negative deflections observed in the difference waveforms were measured and compared by an ANOVA between the age groups. The alpha level was set to $p<.05$.

\section{Analysis of Neural-Behavioral Relation}

To investigate the relation between the magnitude of the early attentional modulation and performance, correlational 
analyses were performed. The attentional modulation of early target processing was calculated for each observer as the mean amplitude difference between target and moving distractor ERPs elicited by the probes at electrode sites and in time intervals of interest. Because younger and older adults differed in the time course of the attention effects, different time windows were chosen for both age groups (P1 effect: 100-125 msec for younger adults, 125-150 msec for older adults; N1 effect: $185-210 \mathrm{msec}$ for both age groups, respectively). The amplitude difference was then correlated with the individual's tracking capacity for each age group separately.

Finally, to delineate individual from age-related differences, we split up the group of older adults based on their overall task performance. In the performance group analysis, we focused only on the older adults. Younger adults' performance was very high overall ( $95 \%$ correct; $S D=$ 0.04; see Results and Figure 1B); thus, a distinction between young high and low performers would not be meaningful. Taking an extreme-group approach (Preacher, Rucker, MacCallum, \& Nicewander, 2005; Feldt, 1961), we divided the older adults into the upper third (i.e., the 13 highest) and lower third (i.e., 13 lowest performers) on mean performance accuracy (for similar procedure, see Nagel et al., 2009). We then compared the mean ERP amplitudes of the two performance groups. Additionally, we compared the tracking performance between the group of high-performing older adults and the group of younger adults.

\section{RESULTS}

\section{Behavioral Tracking Performance}

As can be seen in Figure 1B, tracking accuracy was high for both younger (95\% correct) and older (89\% correct) participants. Older adults, however, performed less well than younger adults, $F(1,73)=13.66, p<.05, \eta^{2}=.16$. Furthermore, as to be expected, RTs were shorter in younger adults than in older adults, $F(1,73)=42.65, p<.05$, $\eta^{2}=.37$.

\section{Overview of Electrophysiological Responses}

In both age groups, ERP waveforms to the task-irrelevant probes elicited the typically observed pattern of an early positive deflection starting at about $100 \mathrm{msec}$ (P1 component), followed by a negative deflection peaking at about 190 msec (N1 component) over occipital-parietal cortex. These early deflections were followed by a prominent P2 component peaking at about $225 \mathrm{msec}$ over central-parietal cortex and less distinct N2 and P3 components (see Figure 3A). The P1 component consisted of two peaks, the first peak with its maximum at parietaloccipital electrodes at about $110 \mathrm{msec}$ and the second peak with its maximum at central-parietal electrodes at about 140 msec. Topographical voltage maps showed similar voltage distributions for younger and older adults for the early P1 and N1 components (Figure 2). The early phase of the P1 component (100-125 msec) was distributed bilaterally over parietal-occipital scalp, whereas the later phase (125-150 msec) showed a more anterior distribution over the central-parietal scalp. The N1 component was distributed bilaterally over parietal-occipital scalp.

Figure 3B shows the mean difference waveforms for the ERPs elicited by the moving distractor probes subtracted from the ERPs elicited by the target probes. The difference waveforms illustrate the time course of the selection process in younger and older adults. At parietal-occipital electrodes, the difference waveforms of older adults showed considerable overlap with the difference waveforms of younger adults, respectively. Both age groups exhibited amplitude differences between target and moving distractor objects at several distinct time intervals: a positive deflection between 100 and $125 \mathrm{msec}$ at parietal-occipital (hereafter early P1 effect) and a negative deflection between 185 and 210 msec at lateral parietal-occipital sites (hereafter N1 effect).

At central-parietal sites, the difference waveform for younger adults showed a positive deflection between 100 and $125 \mathrm{msec}$ similarly to occipital-parietal sites, whereas the peak of the difference waveform of older adults appeared to be shifted in time and reached its peak much later compared with the younger adults, namely at about 140 msec (hereafter delayed P1 effect). Statistical analysis on the peak latencies of the ERP difference waveforms for younger and older adults revealed that the positivity peaked later for older adults compared with younger adults at central-parietal electrode sites (younger adults: $113 \mathrm{msec}$ at $\mathrm{CP} 1 / \mathrm{CP} 2,115 \mathrm{msec}$ at $\mathrm{C} 1 / \mathrm{C} 2$; older adults: $142 \mathrm{msec}$ at CP1/CP2, $142 \mathrm{msec}$ at $\mathrm{C} 1 / \mathrm{C} 2 ; F(1,73)=$ $\left.55.67, p<.05, \eta^{2}=.38\right)$.

\section{Early (100-125 msec) Phase of the P1 at Occipital-Parietal Electrode Sites}

Figure 3A displays the average ERP waveforms for both age groups at parietal-occipital electrodes. An omnibus ANOVA revealed a main effect of Age Group, $F(1,73)=$ $6.65, p<.05, \eta^{2}=.05$, Probe Type, $F(2,146)=8.55, p<$ $.05, \eta^{2}=.03$, a Probe Type $\times$ Electrode Location interaction, $F(2,146)=5.5, p<.05, \eta^{2}=.0009$, and an Age Group $\times$ Probe Type $\times$ Electrode Location interaction, $F(2,146)=3.28, p<.05, \eta^{2}=.0006$, indicating that older adults exhibited a larger P1 component compared with younger adults and that the P1 amplitude effects differed between probe types and electrode locations. In separate analyses for each group, we found for younger adults that the ERP waveforms elicited by target probes were more positive than the waveforms elicited by any distractor probes between 100 and $125 \mathrm{msec}$ (see Figure 3). This impression was confirmed by a main effect of Probe Type, $F(2,74)=3.23, p<.05, \eta^{2}=.07$, and a Probe Type $\times$ Electrode Location interaction, $F(2,74)=6.11, p<.05$, 
$\eta^{2}=.007$. Follow-up pairwise comparisons indicated that this effect could be observed for targets versus moving distractors at $\mathrm{PO} 7 / \mathrm{PO} 8\left(F(1,37)=3.26, p<.05, \eta^{2}=.08\right)$ and PO3/PO4 $\left(F(1,37)=5.95, p<.05, \eta^{2}=.13\right)$ and also for targets versus stationary distractors at PO3/PO4, $F(1$, $37)=7.05, p<.05, \eta^{2}=.16$ (see also Figure 4). For older adults, the ERP waveforms elicited by the different probe types were largest for target probes, closely followed by moving distractor probes, and smallest for stationary distractor probes (see Figure 3). In this age group, only the main effect of Probe Type was reliable, $F(2,72)=6.62$, $p<.05, \eta^{2}=.14$. Pairwise follow-up comparisons showed that the mean amplitude did not differ for targets versus moving distractors $(p>.05)$, but only for targets versus stationary distractors, at all four electrodes sites, $F(1,36)=$ 11.94, $p<.05, \eta^{2}=.22$ (see Figure 4).

The pattern of findings can be summarized as follows. In younger adults, the P1 amplitude between 100 and $125 \mathrm{msec}$ was larger for targets relative to either of the two distractor types, suggesting efficient enhancement of targets as well as suppression of moving distractors to the level of stationary distractors. In older adults, the P1 amplitude was enhanced for targets relative to stationary distractors. However, there was no reliable amplitude difference between targets and moving distractors, suggesting deficient suppression of moving distractors in older adults.

\section{Early (100-125 msec) and Late (125-150 msec) Phase of the P1 at Central-Parietal Electrode Sites}

At central-parietal sites, statistical analyses of the early time window (100-125 msec) revealed a main effect of Probe Type, $F(2,146)=6.00, p<.05, \eta^{2}=.03$, a main effect of Electrode Location, $F(2,146)=42.56, p<.05, \eta^{2}=$ .006 , and an Age Group $\times$ Probe Type interaction, $F(2$, 146) $=3.28, p<.05, \eta^{2}=.007$, indicating that the effect of Probe Type differed between younger and older adults. For younger adults, a repeated-measures ANOVA revealed a main effect of Probe Type, $F(2,74)=4.47, p<.05$,
Figure 4. Mean amplitude differences for younger and older adults at occipital-parietal electrode sites between 100 and $125 \mathrm{msec}$ (first row), central-parietal electrode sites between 100-125 and 125-150 msec (second row), and occipital-parietal electrode sites between 185 and $210 \mathrm{msec}$ (third row). Mean amplitudes are collapsed across four pair of electrodes: $\mathrm{PO} 3 / \mathrm{PO} 4 / \mathrm{PO} 7 /$ PO8 for occipital-parietal electrode sites, $\mathrm{CP} 1 / \mathrm{CP} 2 / \mathrm{C} 1 / \mathrm{C} 2$ for central-parietal sites, and $\mathrm{PO} 7 / \mathrm{PO} 8 / \mathrm{P} 7 / \mathrm{P} 8$ for occipitalparietal electrode sites.

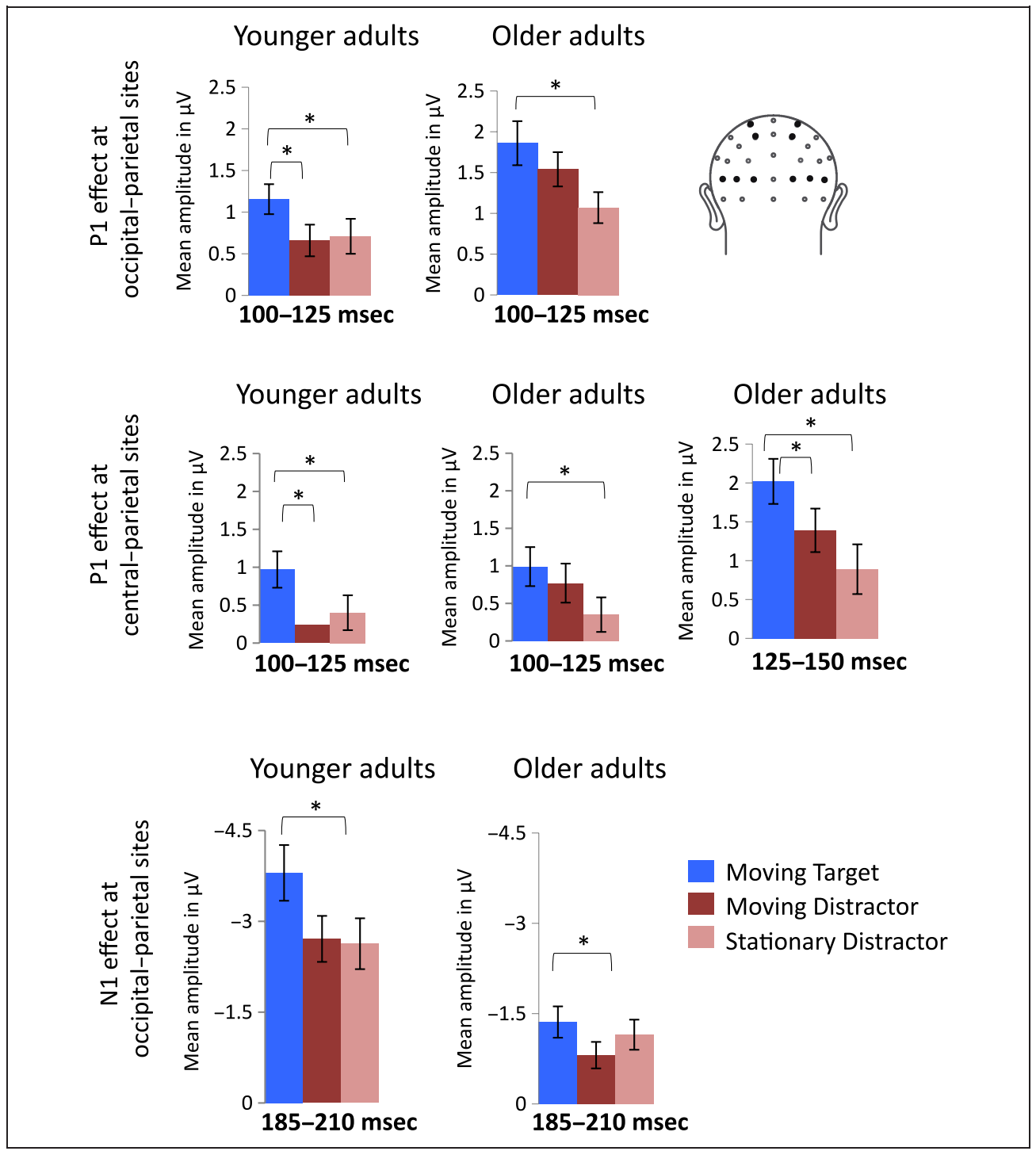


$\eta^{2}=.03$, and electrode location, $F(1,37)=13.34, p<.05$, $\eta^{2}=.007$. Follow-up pairwise comparisons showed that the amplitude for targets was larger than for moving distractors, $F(1,37)=9.30, p<.05, \eta^{2}=.19$, as well as for stationary distractors, $F(1,37)=4.5, p<.05, \eta^{2}=$ .12. In contrast, older adults did not show reliable mean amplitude differences between the targets and the moving distractors during the early phase of the P1 component (see Figure 4). An ANOVA revealed a main effect of electrode location, $F(1,36)=32.43, p<.05, \eta^{2}=.02$, and probe type, $F(2,72)=3.04, p<.05, \eta^{2}=.07$. Follow-up analyses showed that this effect was driven by the amplitude difference between targets and stationary distractors, $F(1,36)=7.48, p<.05, \eta^{2}=.16$; differences in amplitude between targets and moving distractors were not reliable $(p>.05)$.

However, at the later time window (125-150 msec), older adults' ERP waveforms were more positive for targets than for distractors at central-parietal electrode sites (compare Figure 3B). Statistical analysis revealed a main effect of probe type, $F(2,72)=8.55, p<.05, \eta^{2}=.18$, and electrode location, $F(1,36)=14.1, p<.05, \eta^{2}=.01$, and a Probe Type $\times$ Electrode Location interaction, $F(2,72)=$ 3.96, $p<.05, \eta^{2}=.002$. As depicted in Figure 4, mean amplitude differences were reliable for the comparison of targets versus moving distractors at both central-parietal electrode pairs $\left(\mathrm{CP} 1 / \mathrm{CP} 2: F(1,36)=5.73, \eta^{2}=.14\right.$; C1/ C2: $F(1,36)=4.82, \eta^{2}=.11$; all $p$ s $\left.<.05\right)$, as well as for the comparison of targets versus stationary distractors $\left(\mathrm{CP} 1 / \mathrm{CP} 2: F(1,36)=20.25, \eta^{2}=.36 ; \mathrm{C} 1 / \mathrm{C} 2: F(1,36)=\right.$ $15.27, \eta^{2}=.29$; all $\left.p s<.05\right)$. In summary, these results indicate that older adults showed similar amplitude modulation effects as younger adults at central-parietal electrode sites, namely an amplification of the P1 amplitude relative to both moving and stationary distractors. However, relative to younger adults, this task-dependent modulation of amplitude differences was delayed in time.

\section{N1 (185-210 msec) at Occipital-Parietal Electrode Sites}

Younger adults elicited a larger N1 component than older adults. Also, the amplitude of the N1 differed between probe types in both age groups. Given that mean amplitudes between moving and stationary distractor probes did not differ in either Age Group ( $p s>.05$ ), mean amplitudes of target probes were tested against both distractor probes in the following analysis. An overall ANOVA revealed a main effect of Age Group, $F(1,73)=16.37, p<$ $.05, \eta^{2}=.16$, Probe Type, $F(1,73)=23.05, p<.05, \eta^{2}=$ .02 , and an Age Group $\times$ Probe Type interaction, $F(1$, 73) $=8.90, p<.05, \eta^{2}=.005$, and a Probe Type $\times$ Electrode Location interaction, $F(1,73)=5.85, p<.05$, $\eta^{2}=.0003$. For younger adults, statistical analysis revealed a main effect of Probe Type, $F(1,37)=42.45, p<.05, \eta^{2}=$ .34 , and a Probe Type $\times$ Electrode Location interaction, $F(1,37)=7.28, p<.05, \eta^{2}=.005$. Target probes elicited larger amplitudes relative to both distractor types at both electrode sites PO7/PO8, $F(1,37)=24.94, p<.05, \eta^{2}=$ .41 , and at $\mathrm{P} 7 / \mathrm{P} 8, F(1,37)=63.70, p<.05, \eta^{2}=.63$. Similarly, in older adults, the ERP waveforms elicited by target probes were more negative relative to both distractor types, as revealed by a main effect of Probe Type, $F(1$, $36)=5.03, p<.05, \eta^{2}=.07$, and a main effect of Electrode Location, $F(1,36)=7.98, p<.05, \eta^{2}=.06$. These results indicate that both younger and older adults showed enhanced target processing between 185 and 210 msec relative to both distractors. Older adults, however, showed a relatively smaller magnitude of the target enhancement effect as reflected in the smaller effect sizes.

\section{Relation between Early Selection and Tracking Performance in Older Adults}

Figure 5 depicts the relation between the early attentional modulation and tracking capacity in older adults. In older

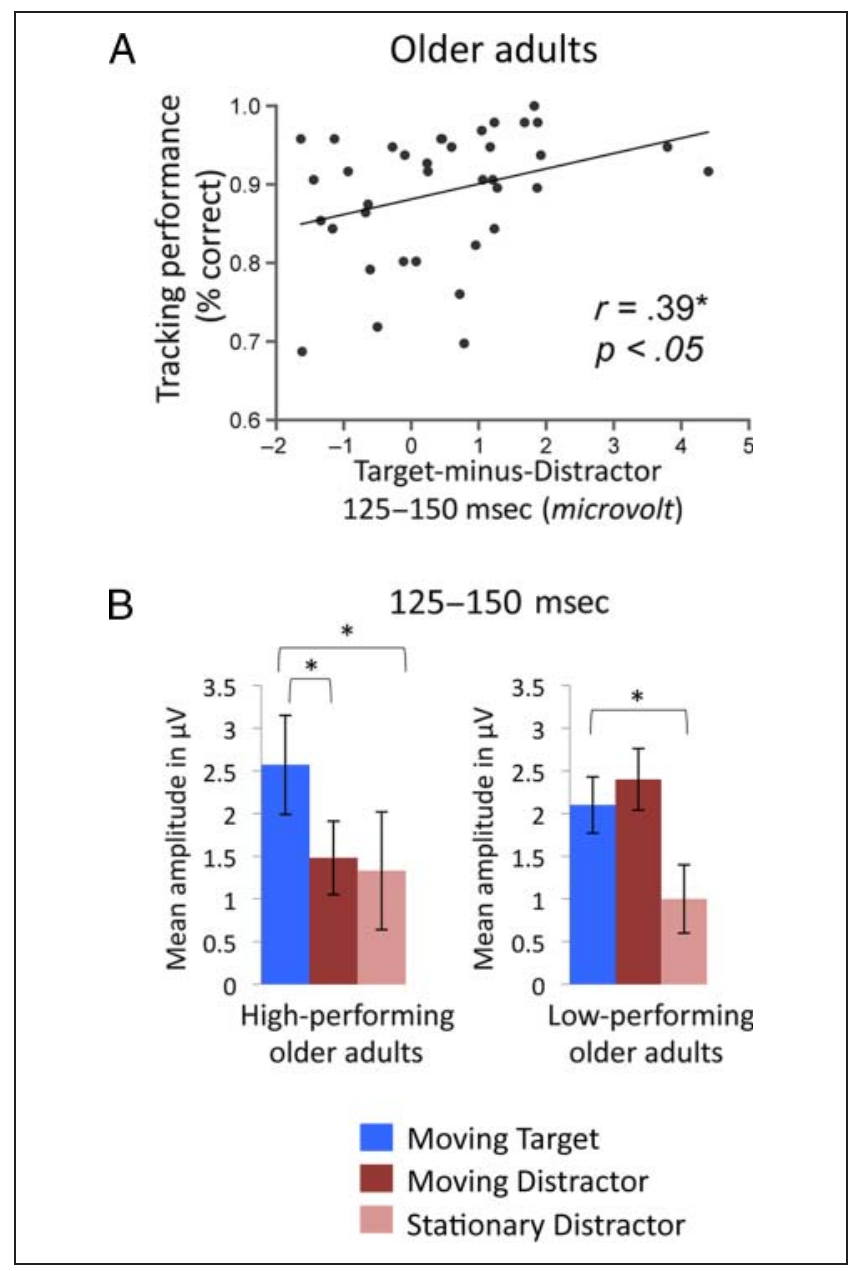

Figure 5. Relationship between the magnitude of the attentional modulation and individual's tracking performance. (A) Correlation between the delayed P1 effect and tracking performance (\% correct) in older adults. (B) Illustration of the delayed P1 modulation in high- and low-performing older adults. 
adults, the magnitude of the delayed P1 modulation at central-parietal electrode sites correlated with tracking performance $(r=0.39, p<.05)$. To follow up on the correlational analysis, we examined subgroups of low- and high-performing older adults separately. Figure $5 \mathrm{C}$ shows the mean amplitudes between 125 and $150 \mathrm{msec}$ for the 13 highest- and the 13 lowest-performing individuals in the group of older adults. Clearly, ERP waveforms of targets were more positive compared with both types of distractors in the high-performing older adults. Statistical analysis revealed a performance Group $\times$ Probe Type interaction for the late phase of the P1 component at all four electrode pairs of interest, $F(1,24)=6.35, p<.05, \eta^{2}=.04$. Follow-up analyses showed that both high- and lowperforming older adults had larger amplitudes for targets relative to stationary distractors (high performers: $F(1,12)=11.28, p<.05, \eta^{2}=.31$; low performers: $F(1$, $\left.12)=9.98, p<.05, \eta^{2}=.48\right)$, but only the high-performing older adults showed a reliable difference between targets and moving distractors, $F(1,12)=6.03, p<.05, \eta^{2}=$ .40 , similar to what we observed in younger adults. These results indicate that the delayed $\mathrm{P} 1$ difference observed in the whole sample of older adults was mainly driven by a high-performing subgroup and that high-performing older adults' pattern of task-related amplitude differences between targets and moving distractors closely resembled the patterns observed in younger adults. Regarding the latter finding, it is worth noting that high-performing older adults and younger adults did not differ reliably in tracking performance $(p>.05)$. For younger adults, there were no statistically reliable correlations, most likely due to the high mean level and the restriction of range in their behavioral performance $(S D=0.15$, for estimated tracking capacity).

\section{DISCUSSION}

It is commonly accepted that older adults are less able to select relevant and ignore irrelevant information relative younger adults (e.g., Milham et al., 2002; Kramer \& Strayer, 2001; Maylor \& Lavie, 1998; Madden \& Gottlob, 1997). The mechanisms underlying this deficit are, however, not yet fully understood. Previous research on age differences in selective attention at early processing stages has mainly used object-based (e.g., Gazzaley et al., 2008) and feature-based (e.g., Zanto et al., 2010) tasks, rather than tasks that require spatial attention to moving objects while irrelevant moving objects are concurrently present in the visual field. Here, we investigated adult age differences in electrophysiological correlates of top-down attentional modulation at early processing stages over visual cortex while participants were tracking multiple moving objects. We used a task in which multiple moving target objects were presented simultaneously with highly distracting objects (identical moving distractors) and less distracting objects (stationary distractors) and asked participants to keep track of the target objects for several seconds. By means of
EEG recordings, we were able to delineate the neural processing of target objects, moving distractor objects, and stationary distractor objects on a millisecond time scale.

Younger adults enhanced processing of target objects relative to distractor objects in the early phase of the P1 component (100-125 msec) over parietal-occipital and central-parietal scalp. Similarly, neural processing was enhanced for target objects relative to distractor objects over parietal-occipital scalp in the time period of the N1 component (185-210 msec). In both time windows, ERP amplitudes were larger for target objects relative to both types of distractor objects, suggesting distinct enhancement of the target objects and efficient suppression of the highly distracting moving objects (compare Figures 3 and 4). The P1 component was distributed over parietaloccipital scalp in the early time interval (100-125 msec) and the posterior N1 component showed a typical bilateral parietal-occipital distribution (Figure 2; cf. Khoe, Mitchell, Reynolds, \& Hillyard, 2005; Gomez Gonzalez, Clark, Fan, Luck, \& Hillyard, 1994). Our findings for younger adults replicate the results by Drew and colleagues (2009), who used a similar design and reported enhancement of the P1 and N1 components for targets relative to distractors. Also, Doran and Hoffman (2010) reported similar N1 effects during MOT in younger adults.

Modulatory effects of attention differed between older and younger adults. In older adults, the mean ERP amplitude of the early phase of the P1 component was largest for targets, followed by moving distractors and then stationary distractors. The more gradual decrease of the P1 amplitude suggests that attentional selection was operating less effectively in older adults. In fact, only the amplitude difference between targets and stationary distractors, but not the difference between targets and moving distractors, was reliable in this early phase of the P1 component. The fact that older adults showed a similar amplitude enhancement for targets relative to stationary objects compared with younger adults indicates that mechanisms of target enhancement were mostly intact in the elderly. In contrast, the finding that moving distractors were processed at a level more similar to targets suggests that older adults had difficulties in suppressing the moving distractors to the level of stationary distractors. Previously, the larger target-related P1 amplitude relative to either of the two types of distractors in the MOT paradigm has been interpreted mainly as target enhancement and the similar P1 amplitudes of stationary and moving distractors as a lack of suppressing the moving distractors (Drew et al., 2009). This interpretation was based on the assumption that suppression would become apparent in an amplitude reduction of the $\mathrm{P} 1$ component for moving distractors relative to stationary distractors (Drew et al., 2009). However, as the experimental design does not provide a clear baseline condition, the lack of difference between ERP amplitudes elicited by moving and stationary distractors in younger adults may just as well indicate suppression of moving distractors to the level of stationary distractors 
(cf. Doran \& Hoffman, 2010). Additionally, the P1 attention effect has been associated with a purely suppressive mechanism, suggesting a decrease in neural strength for unattended stimuli relative to attended stimuli (Luck, 1995; Luck et al., 1994).

Overall, mean ERP amplitudes of the N1 component were smaller in older than in younger adults. Older adults showed a reliable amplitude enlargement for targets relative to both distractor types, similar to what we found in younger adults. The magnitude of the attentional enhancement was, however, reduced in older adults than in younger adults (younger adults: $\eta^{2}=.34$; older adults: $\eta^{2}=.07$, see also Figures 3 and 4 ). The N1 effect has been linked to a capacity-limited discriminative process applied to attended stimuli, facilitating the processing within the focus of attention (Mangun \& Hillyard, 1991; Luck et al., 1990). Hence, the results of our study suggest that enhancement of target object processing is impaired in old age.

Informed by recent studies suggesting that suppression may be delayed rather than completely absent among older adults (Jost et al., 2011; Gazzaley et al., 2008), we further investigated the time course of the selection process by examining ERP difference waveforms at later points in time. In older adults only, the difference waveforms revealed an amplitude difference between targets and moving distractors $125-150 \mathrm{msec}$ after probe onset over central-parietal cortex (Figure 3B). Importantly, in this later time window, older adults managed to suppress moving distractors efficiently and showed a pattern of amplitude differences that resembled the pattern of younger adults in the earlier time interval. The time delay of attentional selection was only present at more central-parietal sites, but not observable at parietal-occipital electrode sites. This finding is consistent with the observation that many functional distinctions between younger and older adults occur along the anterior-posterior axis (Cabeza, Anderson, Locantore, \& McIntosh, 2002; Grady et al., 1994). A series of neuroimaging studies reported an agerelated increase of activation in more anterior brain regions, whereas activation in posterior brain regions was lower relative to younger adults (Davis, Dennis, Daselaar, Fleck, \& Cabeza, 2008; Madden, 2007; Madden, Turkington, Provenzale, Hawk, \& Hoffman, 1997). Furthermore, the finding that the delayed attention effect in older adults was more localized relative to the early attention effect in younger adults suggests that different neural sources may underlie the attentional selection in the two age groups. There was no difference in the time course of the N1 modulation between younger and older adults (Figure 3). Overall, then, we found that efficient selection emerged later in time in older adults relative to younger adults during the first positive deflection (P1 component), but not in subsequent processing stages (N1 component).

ERP studies showed that under certain circumstances perceptual processing can be delayed in older adults (e.g., Curran, Hills, Patterson, \& Strauss, 2001; for a review, see Kok, 2000). Such findings may be construed to support the notion of general slowing of information processing with advancing age (Salthouse, 1996, 2000). However, age-related cognitive slowing is not consistently expressed at the level of ERP latencies (Bashore, Osman, \& Heffley, 1989). Many EEG studies of cognitive and perceptual aging observed age effects in amplitudes but not in latencies (e.g., Werkle-Bergner, Shing, Müller, Li, \& Lindenberger, 2009; Iragui, Kutas, Mitchiner, \& Hillyard, 1993; for an overview, see also Guerreiro et al., 2010). In this study, we were interested in age-related differences in the time course of a specific cognitive mechanism, namely top-down attentional selection during visual perceptual processing. By computing difference waveforms between the ERP waveforms elicited by relevant objects (target probes) and distracting objects (moving distractor probes), we were able to identify the time course of the selection process. We found that older adults' selection mechanism is delayed relative to younger adults. Importantly, this delay in selection would easily be misconstrued as a complete absence of selection among older adults if the relevant analyses were restricted to the time window at which younger adults show the largest amplitude differences between targets and moving distractors.

The delay of attentional selection in older adults parallels, in part, Gazzaley et al.'s finding of a suppression delay during working memory encoding in older adults (Gazzaley et al., 2008). In that study, individual differences in memory performance within the group of older adults were not associated with the individual differences in delayed suppression. On this basis, the authors concluded that selection needs to operate early to safeguard later processing stages from processing irrelevant information. Note, however, that older adults' delayed suppression effects occurred about 500-650 msec after stimulus onset and were measured by means of alpha desychronization over occipital cortex, whereas the early selection process in younger adults was indexed by modulations in the P1 and N1 components over occipital cortex. The different indices of suppression and the rather long delay suggest that the two measures may have indexed mechanisms that differ in function, substrates, and efficiency. Apparently, the early selection process indexed by P1 and N1 modulations employed by younger adults was functionally necessary for performing well in the task, whereas the later selection process indexed by alpha desynchronization was not. In contrast, in this study, the age-related latency shift of the selection process was rather small $(25 \mathrm{msec})$ and occurred within the time window of the first positive deflection of visual processing (i.e., P1 component). The magnitude of the delayed P1 attention effect in older adults predicted tracking performance. Whereas low-performing older adults seemed to deploy similar amounts of attentional resources to all moving objects at any point in time, regardless whether they were targets or distractors, high-performing older adults showed selective target processing during the late time interval. In 
particular, high-performing older adults showed distinct target enhancement relative to both distractor types, paralleling selective target processing in the group of younger adults in the early time interval (compare Figure 4). In the present task, then, all what separated high-performing older adults from younger adults was a 25 -msec delay in distractor suppression. The absence of reliable performance differences between younger adults and highperforming older adults, in the presence of a temporal delay in suppression among the latter relative to the former, can be interpreted in different ways. First, it may mean that attentional visual selection of moving targets in the presence of moving distractors is fully unimpaired in a high-functioning segment of the elderly population because the slight delay in suppression did not result in behavioral impairments. Alternatively and presumably more likely, this delay may be functionally relevant, but the present paradigm may not have been sufficiently sensitive to pick up its detrimental effects. In particular, performance in the present task was generally quite high. It remains to be investigated whether more taxing task conditions (e.g., more stimuli, faster movements, or longer movement periods) would reveal the detrimental consequences of age-associated selection delays, however small, on tracking performance. Clearly, further studies are needed to discriminate between the two interpretations.

Our results reveal that aging affects the earliest stage of attentional modulation of visual processing, namely the modulation of the P1 component (Hillyard \& AnlloVento, 1998). Adult age differences in attentional modulation have been observed at the stage of the N1 component, both in terms of amplitude modulations (de Fockert et al., 2009) and latency differences (i.e., selection negativity; Zanto et al., 2010). The present results suggest that normal aging affects attention-induced modulations of the N1 component during MOT to a lesser degree than attention-induced modulations at the level of the P1 component. The differences between our results and many previous findings can be accounted for by several significant differences between our and previous studies. The most striking difference is the fact that MOT involves spatial attention, whereas other studies used nonspatial tasks. The P1 component is particularly sensitive to spatial attention, whereas the N1 component is mostly sensitive to object- and feature-based attention (Martinez, Ramanathan, Foxe, Javitt, \& Hillyard, 2007; Martinez et al., 2006). Thus, adult age differences in attentional selection may emerge as delayed modulations of the P1 component in spatial attention tasks where visual stimulus features are not relevant for performance but are revealed in modulations of the N1 component in object- or featurebased attention tasks. However, it should be noted that Gazzaley et al. (2008) also reported age differences at the level of the P1 component using complex stimuli such as faces and scenes. They found an amplitude difference of the P1 component between younger and older adults, but no difference in the latency of the P1 modulation.
The association between the magnitude of P1 modulation and tracking performance observed here stresses the functional significance of selective processing at such early processing stages. Research in younger adults has shown that individual's effectiveness in gating sensory information (i.e., amplitude of $\mathrm{P} 1 / \mathrm{N} 1$ components) predicts higher-order cognitive functions such as working memory (Rutman, Clapp, Chadick, \& Gazzaley, 2010; Brumback, Low, Gratton, \& Fabiani, 2004). Hence, the relation between the delayed P1 attention effect and tracking performance observed here is in support of the notion that age-related declines in early selective processing contribute to older adults' deficit in a wide range of cognitive functions (Gazzaley, Cooney, Rissman et al., 2005; Chao \& Knight, 1997).

The age-related alterations in attentional modulation observed in this study may reflect an age-related vulnerability of bias signals from prefrontal cortical regions, which are known to undergo pronounced changes in normal aging (Lindenberger et al., in press). Attention is assumed to act via bias signals from the prefrontal regions that, in return, modulate processing in extrastriate sensory cortex (Chadick \& Gazzaley, 2011; Miller, Vytlacil, Fegen, Pradhan, \& D’Esposito, 2011; Gazzaley, Rissman, et al., 2007). Agerelated impairments in these top-down control circuitries are likely underlying the compromised selection during visual processing. Recent findings suggest an age-related decrease in selective processing of objects in the visual cortex, independent of attention (Carp, Gmeindl, \& ReuterLorenz, 2011; Carp, Park, Polk, \& Park, 2011; Park et al., 2004). These age-related increases in dedifferentiation may be due to age-related declines in neuromodulation resulting in less distinctive perceptual representations (cf. Li, Lindenberger, \& Sikström, 2001). In the case of MOT, older adults' less distinctive spatial representations of moving objects in the visual processing pathways may, in turn, demand more attention to compensate for the low spatial resolution inherent to the aging brain. According to this view, the altered P1 modulation in older adults may then be a reflection of an inability to fully compensate for the increase in perceptual dedifferentiation in the visual cortex in older adults.

Efficient separation of target from distractor objects is one critical element of successful tracking performance, but MOT likely involves other processes that may further contribute to the age-related decline in performance. Given the association between MOT performance and working memory capacity observed in younger adults (Oksama \& Hyönä, 2004), the age-related impairment in working memory capacity (Gazzaley, Sheridan, Cooney, \& D’Esposito, 2007; Babcock \& Salthouse, 1990) is another potential factor that contributes to the age-related decline in MOT performance. Furthermore, age-related differences in sensory memory may play a role. Tracking tasks that involve the detection of deviations of motion trajectories depend on sensory memory of the motion trajectory, as they require the comparison of a current motion direction to the just-observed motion direction 
(Narasimhan, Tripathy, \& Barrett, 2009). Possibly, such memory traces also play a role during classic MOT tasks (Shooner, Tripathy, Bedell, \& Ogmen, 2010). Prominent age-related declines, starting at age 30, have been observed in the ability to detect deviations of linear motion trajectories in the absence of distractor objects (Kennedy, Tripathy, \& Barrett, 2009). Such findings insinuate that age differences in sensory memory of motion trajectories or working memory or the interaction effects of the two also contribute to the age-related decline in MOT performance.

In conclusion, the present ERP results provide direct electrophysiological evidence that normal aging affects attentional selection to resolve competition of visual information at the earliest stage of attentional modulation during visual processing, namely the P1 component. In part, these age-related impairments in selective processing of targets over distractors contribute to the agerelated decline in MOT performance. These results are in line with the inhibitory deficit hypothesis of aging (Hasher \& Zacks, 1988) and show that older adults process irrelevant information similar to relevant information at an early stage within the visual processing pathways. The inefficient attentional modulation at early processing stages may increase the noise levels at later stages of processing, possibly leading to deficits in higherorder cognition. However, effects of top-down attentional selection were not completely lost in older adults but emerged later in time. There was substantial variability in tracking performance among older adults. This variability was associated with individual differences in the ability to suppress moving distractors, suggesting that suppression mechanisms in visual attention are relatively intact in some older adults, and compromised in others.

\section{Acknowledgments}

We thank the student assistants for help with data collection. Viola S. Störmer has been supported by the International Max Planck Research School: The Life Course: Evolutionary and Ontogenetic Dynamics.

Reprint requests should be sent to Viola S. Störmer, Vision Sciences Laboratory, Harvard University, Cambridge, MA or via e-mail: vstormer@fas.harvard.edu.

\section{REFERENCES}

Alain, C., \& Woods, D. L. (1999). Age-related changes in processing auditory stimuli during visual attention: Evidence for deficits in inhibitory control and sensory memory. Psychology and Aging, 14, 507-519.

Babcock, R. L., \& Salthouse, T. A. (1990). Effects of increased processing demands on age-differences in working memory. Psychology and Aging, 5, 421-428.

Bashore, T. R., Osman, A., \& Heffley, E. F. (1989). Mental slowing in elderly persons: A cognitive psychophysiological analysis. Psychology and Aging, 4, 235-244.

Brumback, C. R., Low, K. A., Gratton, G., \& Fabiani, M. (2004). Sensory ERPs predict differences in working memory span and fluid intelligence. NeuroReport, 15, 373-376.
Cabeza, R., Anderson, N. D., Locantore, J. K., \& McIntosh, A. R. (2002). Aging gracefully: Compensatory brain activity in high-performing older adults. Neuroimage, 17, 1394-1402.

Carp, J., Gmeindl, L., \& Reuter-Lorenz, P. A. (2011). Age differences in the neural representation of working memory revealed by multi-voxel pattern analysis. Frontiers in Human Neuroscience, 4, 217.

Carp, J., Park, J., Polk, T. A., \& Park, D. C. (2011). Age differences in neural distinctiveness revealed by multi-voxel pattern analysis. Neuroimage, 56, 736-743.

Cavanagh, P., \& Alvarez, G. A. (2005). Tracking multiple targets with multifocal attention [review]. Trends in Cognitive Sciences, 9, 349-354.

Chadick, J. Z., \& Gazzaley, A. (2011). Differential coupling of visual cortex with default or frontal-parietal network based on goals. Nature Neuroscience, 14, 830-832.

Chao, L. L., \& Knight, R. T. (1997). Prefrontal deficits in attention and inhibitory control with aging. Cerebral Cortex, 7, 63-69.

Cline, D., Hofstetter, H. W., \& Griffin, J. R. (1997). Dictionary of visual science (4th ed.). Boston, MA: Butterworth.

Curran, T., Hills, A., Patterson, M. B., \& Strauss, M. E. (2001). Effects of aging on visuaospatial attention: An ERP study. Neuropsychologia, 39, 288-301.

Czigler, I., Csibra, G., \& Ambro, A. (1994). Event-related potentials and aging-Identification of deviant visual-stimuli. Journal of Psychophysiology, 8, 193-210.

Davis, S. W., Dennis, N. A., Daselaar, S. M., Fleck, M. S., \& Cabeza, R. (2008). Que PASA? The posterior-anterior shift in aging. Cerebral Cortex, 18, 1201-1209.

de Fockert, J. W., Ramchurn, A., van Velzen, J., Bergstrom, Z., \& Bunce, D. (2009). Behavioral and ERP evidence of greater distractor processing in old age. Brain Research, 1282, $67-73$.

Doran, M. M., \& Hoffman, J. E. (2010). The role of visual attention in multiple object tracking: Evidence from ERPs. Attention Perception \& Psychophysics, 72, 33-52.

Drew, T., McCollough, A. W., Horowitz, T. S., \& Vogel, E. K. (2009). Attentional enhancement during multiple-object tracking. Psychonomic Bulletin \& Review, 16, 411-417.

Duncan, J., Humphreys, G., \& Ward, R. (1997). Competitive brain activity in visual attention. Current Opinion in Neurobiology, 7, 255-261.

Fabiani, M., Low, K. A., Wee, E., Sable, J. J., \& Gratton, G. (2006). Reduced suppression or labile memory? Mechanisms of inefficient filtering of irrelevant information in older adults. Journal of Cognitive Neuroscience, 18, 637-650.

Feldt, L. S. (1961). The use of extreme groups to test for the presence of a relationship. Psychometrika, 26, 307-316.

Gazzaley, A., Clapp, W., Kelley, J., McEvoy, K., Knight, R. T., \& D'Esposito, M. (2008). Age-related top-down suppression deficit in the early stages of cortical visual memory processing. Proceedings of the National Academy of Sciences, U.S.A., 105, 13122-13126.

Gazzaley, A., Cooney, J. W., McEvoy, K., Knight, R. T., \& D’Esposito, M. (2005). Top-down enhancement and suppression of the magnitude and speed of neural activity. Journal of Cognitive Neuroscience, 17, 507-517.

Gazzaley, A., Cooney, J. W., Rissman, J., \& D’Esposito, M. (2005). Top-down suppression deficit underlies working memory impairment in normal aging. Nature Neuroscience, 8, 1298-1300.

Gazzaley, A., Rissman, J., Cooney, J., Rutman, A., Seibert, T., Clapp, W., et al. (2007). Functional interactions between prefrontal and visual association cortex contribute to top-down modulation of visual processing. Cerebral Cortex, 17, I125-I135. 
Gazzaley, A., Sheridan, M. A., Cooney, J. W., \& D'Esposito, M. (2007). Age-related deficits in component processes of working memory. Neuropsychology, 21, 532-539.

Geigy, J. R. (1977). Wissenschaftliche tabellen [scientific tables]. Basel: J.R. Geigy AG.

Gomez Gonzalez, C. M., Clark, V. P., Fan, S., Luck, S. J., \& Hillyard, S. A. (1994). Sources of attention-sensitive visual event-related potentials. Brain Topography, 7 , 41-51.

Grady, C. L., Maisog, J. M., Horwitz, B., Ungerleider, L. G., Mentis, M. J., Salerno, J. A., et al. (1994). Age-related changes in cortical blood-flow activation during visual processing of faces and location. Journal of Neuroscience, 14, 1450-1462.

Green, J. J., Conder, J. A., \& McDonald, J. J. (2008). Lateralized frontal activity elicited by attention-directing visual and auditory cues. Psychophysiology, 45, 579-587.

Guerreiro, M. J. S., Murphy, D. R., \& Van Gerven, P. W. M. (2010). The role of sensory modality in age-related distraction: A critical review and a renewed view. Psychological Bulletin, 136, 975-1022.

Hasher, L., \& Zacks, R. T. (1988). The psychology of learning and motivation. New York: Academic.

Heinze, H. J., Luck, S. J., Mangun, G. R., \& Hillyard, S. A. (1990). Visual event-related potentials index focused attention within bilateral stimulus arrays. 1. Evidence for early selection. Electroencephalography and Clinical Neurophysiology, 75, 511-527.

Heinze, H. J., Mangun, G. R., Burchert, W., Hinrichs, H., Scholz, M., Munte, T. F., et al. (1994). Combined spatial and temporal imaging of brain activity during visual selective attention in humans. Nature, 372, 543-546.

Hillyard, S. A., \& Anllo-Vento, L. (1998). Event-related brain potentials in the study of visual selective attention. Proceedings of the National Academy of Sciences, U.S.A., 95, 781-787.

Hillyard, S. A., Mangun, G. R., Woldorff, M. G., \& Luck, S. J. (1995). Neural systems mediating selective attention. In M. S. Gazzaniga (Ed.), The cognitive neurosciences (pp. 665-681). Cambridge, MA: MIT Press.

Hillyard, S. A., Vogel, E. K., \& Luck, S. J. (1998). Sensory gain control (amplification) as a mechanism of selective attention: Electrophysiological and neuroimaging evidence. Philosophical Transactions of the Royal Society of London, Series B, Biological Sciences, 353, 1257-1270.

Iragui, V. J., Kutas, M., Mitchiner, M. R., \& Hillyard, S. A. (1993). Effects of aging on event-related brain potentials and reaction-times in an auditory oddball task. Psychophysiology, 30, 10-22.

Jost, K., Bryck, R. L., Vogel, E. K., \& Mayr, U. (2011). Are old adults just like low working memory young adults? Filtering efficiency and age differenes in visual working memory. Cerebral Cortex, 21, 1147-1154.

Kastner, S., \& Pinsk, M. A. (2004). Visual attention as a multilevel selection process. Cognitive Affective $\mathcal{E}$ Behavioral Neuroscience, 4, 483-500.

Kennedy, G. J., Tripathy, S. P., \& Barrett, B. T. (2009). Early age-related decline in the effective number of trajectories tracked in adult human vision. Journal of Vision, 9 , $1-10,21$.

Khoe, W., Mitchell, J. F., Reynolds, J. H., \& Hillyard, S. A. (2005). Exogenous attentional selection of transparent superimposed surfaces modulates early event-related potentials. Vision Research, 45, 3004-3014.

Kok, A. (2000). Age-related changes in involuntary and voluntary attention as reflected in components of the event-related potential (ERP). Biological Psychology, 54, 107-143.
Kramer, A. F., \& Strayer, D. L. (2001). Influence of stimulus repetition on negative priming. Psychology and Aging, 16, 580-587.

Kritikos, A., McNeill, J., \& Paviis, A. (2008). Temporal dissociation between distractors and targets: The impact of residual distractor processing on target responses. Journal of Motor Behavior, 40, 29-42.

Lehrl, S. (1977). Mehrfachwahl-Wortschatz-test B [multiple-choice knowledge test-B (MWT-B)]. Erlangen, Germany: Straube.

Li, S. C., Lindenberger, U., Hommel, B., Aschersleben, G., Prinz, W., \& Baltes, P. B. (2004). Transformations in the couplings among intellectual abilities and constituent cognitive processes across the life span. Psychological Science, 15, 155-163.

Li, S. C., Lindenberger, U., \& Sikström, S. (2001). Aging cognition: From neuromodulation to representation. Trends in Cognitive Sciences, 5, 479-486.

Lindenberger, U., Burzynska, A. Z., \& Nagel, I. E. (in press). Heterogeneity in frontal-lobe aging. In D. T. Stuss \& R. T. Knight (Eds.), Principles of frontal lobe functions (2nd ed.). New York: Oxford University Press.

Luck, S. J. (1995). Multiple mechanisms of visual-spatial attention: Recent evidence from human electrophysiology. Behavioural Brain Research, 71, 113-123.

Luck, S. J., Heinze, H. J., Mangun, G. R., \& Hillyard, S. A. (1990). Visual event-related potentials index focused attention within bilateral stimulus arrays. 2 Functional dissociation of P1 and N1 components. Electroencephalography and Clinical Neurophysiology, $75,528-542$

Luck, S. J., Hillyard, S. A., Mouloua, M., Woldorff, M. G., Clark, V. P., \& Hawkins, H. L. (1994). Effects of spatial cuing on luminance detectability: Psychophysical and electrophysiological evidence for early selection. Journal of Experimental Psychology: Human Perception and Performance, 20, 887-904.

Madden, D. J. (2007). Aging and visual attention. Current Directions in Psychological Science, 16, 70-74.

Madden, D. J., \& Gottlob, L. R. (1997). Adult age differences in strategic and dynamic components of focusing visual attention. Aging Neuropsychology and Cognition, 4, $185-210$.

Madden, D. J., Turkington, T. G., Provenzale, J. M., Hawk, T. C., \& Hoffman, J. M. (1997). Selective and divided visual attention: Age-related changes in regional cerebral blood flow measured by (H2O)-O-15 PET. Human Brain Mapping, 5, 389-409.

Mager, R., Bullinger, A. H., Brand, S., Schmidlin, M., Scharli, H., Muller-Spahn, F., et al. (2007). Age-related changes in cognitive conflict processing: An event-related potential study. Neurobiology of Aging, 28, 1925-1935.

Mangun, G. R., \& Hillyard, S. A. (1991). Modulations of sensory-evoked brain potentials indicate changes in perceptual processing during visual spatial priming. Journal of Experimental Psychology: Human Perception and Performance, 17, 1057-1074.

Martinez, A., Anllo-Vento, L., Sereno, M. I., Frank, L. R., Buxton, R. B., Dubowitz, D. J., et al. (1999). Involvement of striate and extrastriate visual cortical areas in spatial attention. Nature Neuroscience, 2, 364-369.

Martinez, A., Ramanathan, D. S., Foxe, J. J., Javitt, D. C., \& Hillyard, S. A. (2007). The role of spatial attention in the selection of real and illusory objects. Journal of Neuroscience, 27, 7963-7973.

Martinez, A., Teder-Sälejärvi, W., Vazquez, M., Molholm, S., Foxe, J. J., Javitt, D. C., et al. (2006). Objects are highlighted by spatial attention. Journal of Cognitive Neuroscience, $18,298-310$ 
Maylor, E. A., \& Lavie, N. (1998). The influence of perceptual load on age differences in selective attention. Psychology and Aging, 13, 563-573.

Milham, M. P., Erickson, K. I., Banich, M. T., Kramer, A. F., Webb, A., Wszalek, T., et al. (2002). Attentional control in the aging brain: Insights from an fMRI study of the Stroop task. Brain and Cognition, 49, 277-296.

Miller, B. T., Vytlacil, J., Fegen, D., Pradhan, S., \& D'Esposito, M. (2011). The prefrontal cortex modulates category selectivity in human extrastriate cortex. Journal of Cognitive Neuroscience, 23, 1-10.

Nagel, I. E., Preuschhof, C., Li, S. C., Nyberg, L., Backman, L., Lindenberger, U., et al. (2009). Performance level modulates adult age differences in brain activation during spatial working memory. Proceedings of the National Academy of Sciences, U.S.A., 106, 22552-22557.

Nagel, I. E., Werkle-Bergner, M., Li, S.-C., \& Lindenberger, U. (2007). Perception. In J. E. Birren (Ed.), Encyclopedia of gerontology: Age, aging, and the aged (Vol. 2, 2nd ed., pp. 334-342). Amsterdam: Elsevier.

Narasimhan, S., Tripathy, S. P., \& Barrett, B. T. (2009). Loss of positional information when tracking multiple moving dots: The role of visual memory. Vision Research, 49, $10-27$.

Oksama, L., \& Hyönä, J. (2004). Is multiple object tracking carried out automatically by an early vision mechanism independent of higher-order cognition? An individual difference approach. Visual Cognition, 11, 631-671.

Park, D. C., Polk, T. A., Park, R., Minear, M., Savage, A., \& Smith, M. R. (2004). Aging reduces neural specialization in ventral visual cortex. Proceedings of the National Academy of Sciences, U.S.A., 101, 13091-13095.

Preacher, K. J., Rucker, D. D., MacCallum, R. C., \& Nicewander, W. A. (2005). Use of the extreme group approaches: A critical reexamination and new recommendations. Psychological Methods, 10, 178-192.

Pylyshyn, Z. W., \& Storm, R. W. (1988). Tracking multiple independent targets evidence for a parallel tracking mechanism. Spatial Vision, 3, 179-198.

Rabbitt, P. (1965). An age-decrement in the ability to ignore irrelevant information. Journal of Gerontology, 20, 233-238.

Rutman, A. M., Clapp, W. C., Chadick, J. Z., \& Gazzaley, A. (2010). Early top-down control of visual processing predicts working memory performance. Journal of Cognitive Neuroscience, 22, 1224-1234

Salthouse, T. A. (1996). The processing-speed theory of adult age differences in cognition. Psychological Review, 103, 403-428

Salthouse, T. A. (2000). Aging and measures of processing speed. Biological Psychology, 54, 35-54.

Schmitz, T. W., Cheng, F. H. T., \& De Rosa, E. (2010). Failing to ignore: Paradoxical neural effects of perceptual load on early attentional selection in normal aging. Journal of Neuroscience, 30, 14750-14758.

Sekuler, R., McLaughlin, C., \& Yotsumoto, Y. (2008). Age-related changes in attentional tracking of multiple moving objects. Perception, 37, 867-876.

Shooner, C., Tripathy, S. P., Bedell, H. E., \& Ogmen, H. (2010). High-capacity, transient retention of direction-of-motion information for multiple moving objects. Journal of Vision, 10, 8.

Störmer, V. S., Li, S. C., Heekeren, H. R., \& Lindenberger, U. (2011). Feature-based interference from unattended visual field during attentional tracking in younger and older adults. Journal of Vision, 11, 1-12.

Trick, L. M., Perl, T., \& Sethi, N. (2005). Age-related differences in multiple-object tracking. Journals of Gerontology, Series B, Psychological Sciences and Social Sciences, 60, P102-P105.

Velhagen, K., \& Broschmann, D. (2005). Tafeln zur Prüfung des Farbensinns [Table of tests for color blindness]. Stuttgart: Thieme.

Wechsler, D. (1958). The measurement and appraisal of adult intelligence (4th ed.). Baltimore: Williams \& Wilkins.

Werkle-Bergner, M., Shing, Y. L., Muller, V., Li, S. C., \& Lindenberger, U. (2009). EEG gamma-band synchronization in visual coding from childhood to old age: Evidence from evoked power and inter-trial phase locking. Clinical Neurophysiology, 120, 1291-1302.

West, R., \& Alain, C. (2000). Age-related decline in inhibitory control contributes to the increased Stroop effect observed in older adults. Psychophysiology, 37, 179-189.

Zanto, T. P., Toy, B., \& Gazzaley, A. (2010). Delay in neural processing during working memory encoding in normal aging. Neuropsychologie, 48, 13-25.

Zysset, S., Schroeter, M. L., Neumann, J., \& von Cramon, D. Y. (2007). Stroop interference, hemodynamic response and aging: An event-related fMRI study. Neurobiology of Aging, 28, 937-946. 